\title{
Shaping professional identity: a descriptive qualitative study on Health and Rehabilitation final year students in higher education
}

\author{
Amshuda Sonday, BSc OT (UWC); M. Early Childhood Intervention (UP); PhD (UCT). \\ http://orcid.org/0000-000 I-9973-74I3 \\ Senior Lecturer and Head of Division of Occupational Therapy, Department of Health and Rehabilitation Sciences, University of \\ Cape Town, South Africa.
}

Background: Professional identity represents a person's philosophy of their profession. This identity defines what it means to be and act as a professional.

Aim: This paper will describe the factors that shaped the professional identity of students in Occupational Therapy, Physiotherapy and Communication Sciences Disorders during their four years (2015 - 2018) of studies in the Faculty of Health Sciences in a higher education institution.

Methodology: A descriptive qualitative design was used to describe the factors that emerged. Seven participants were purposively selected from the Faculty of Health Sciences. Individual interviews and a focus group with participants were conducted. Data were analysed inductively.

Findings: The results generated the theme 'The curriculum and experiences within practice and professional environments shape professional identity'. The findings highlighted how critical events in higher education may have influenced the participants to develop a professional identity.

Conclusion: The curriculum played an integral role in defining how the narrative for each participant was played out and how professional and practice environments greatly shaped the students' developing professional self.

Keywords: curriculum, professional and practice environments, health and rehabilitation sciences, undergraduate rehabilitation education

\section{INTRODUCTION}

This paper describes the factors that shaped the professional identity of Occupational Therapy, Physiotherapy and Communication Sciences Disorders students during their four years $(2015$ - 20I8) of study in the Faculty of Health Sciences at the University of Cape Town. The paper provides the context in which the study was conducted and offers a brief review of the literature in relation to curriculum content, professional \& practice environments, and the role of professional identity in the developing self.

\section{BACKGROUND}

Professional identity is a conscious embodiment of the way a professional defines who they are and the way they choose to act and represent themselves. This representation is defined by the philosophy of a particular profession'. Identity is developed and shaped by the experiences of students as they negotiate their roles and positioning within the higher education environments. Although being a student at a university is considered to be a prestigious opportunity, critical events in higher education can impact or influence how health sciences students negotiate their professional identity within a health sciences faculty ${ }^{2}$. The roles universities play in developing countries like South Africa, are those of growth and development ${ }^{2}$. Universities are seen as ideological mechanisms for taking on these roles; where governments fail to do $\mathrm{so}^{2}$. Amongst other uncertainties, higher education in South Africa has been experiencing a fees crisis since 2015, where the lack of government subsidies to universities placed pressure on students and their families with the annual increases in student tuition fees ${ }^{3}$. This crisis culminated in 2015 in the \#feesmustfall movement, which saw students in higher education from all over South Africa rise up in protest against the fee increases. The higher education crisis in South Africa during 2015 and 2018 , has contributed to universities and the health professions in a continuous state of change and uncertainty. This continuous state of change may influence the personal / professional identity of health professionals within the practice contexts in which they find themselves. In considering the continuously changing South African higher education context, health professionals such as occupational therapists, physiotherapists and communication sciences disorders graduates are having to reflect on who they are, and how they choose to respond to changing practice contexts.

There has been little research around how health and rehabilitation (H\&R) students establish their professional identities within a four year degree programme in higher education. It was important to understand how the development of professional identity occurs, and what areas are crucial to enhance their own identity development. Identity development is critical in defining and shaping who the graduating health professional chooses to become and why this is important.

\section{LITERATURE REVIEW}

Professional identity is described as an internal identity that reflects 
choices of beliefs, characteristics and commitments of the self and is further developed or conditioned by experiences in practice ${ }^{4}$. Professional identity will continue to develop throughout the professional lifespan ${ }^{4}$. Personal awareness can be identified as a key to professional identity formation, where the conscious and unconscious beliefs, attitudes, emotions, psychological and cultural background influence the care provided by the health professionals. The awareness of these factors enables the health professional to better serve their patients and themselves ${ }^{4}$.

Occupational therapists have many potential individual and collective professional identities that vary according to their understanding of their identity within different historical and social environments'. Accordingly, the professional identities of occupational therapists should reflect their changing practice context. Occupational therapy needs to articulate its own knowledge base. A healthy professional identity will depend on high levels of autonomy and clinical discretion enabling occupational therapists to draw on their own skills and knowledge within given situations'.

It is argued that occupational therapists should utilise the changing professional order that is characterised by the diversity of practice in order to negotiate a new individual professional identity'. Historically, the professional identities of occupational therapists were less strongly defined than those of other professionals and based on narrow, fixed beliefs such as holism and clientcenteredness'. This has been attributed to a lack of understanding of the purpose and nature of the role of occupational therapists within multidisciplinary teams. This thinking is being challenged as there are calls to redesign occupational therapy work roles in a manner which allows skills to be used more flexibly and which allows an opportunity for innovation and creativity within broader, inter-clinical practices'.

In a study on the development of professional identities within the nursing community ${ }^{5}$, it was found that professional identities continually develop. Professional identities start to develop before entering tertiary education and then evolve during studying, clinical experiences and subsequent careers. However, the study highlighted the importance of education and its effects on professional identity; as it is during this time period that professionals gain the professional knowledge and skills which distinguish them from other occupations.

Locating the individual at the core of their own identity, is the precursor for the concept of occupational identity ${ }^{6}$. This form of identity may be influenced by society having an influence on how individual identities are then shaped ${ }^{6}$. Socially constructed identities result from the interplay between the individual and society ${ }^{7}$. This therefore emphasises the importance of considering the role of context in the development of the self. In a doctoral study on school-based occupational therapists, the author found that occupational identity formed the basis to how occupational therapists negotiated schooling environments that impacted on their developing professional identity ${ }^{8}$.

\section{Curriculum and professional identity}

Brandt discussed his experience of professional identity formation that was achieved through interprofessional learning and encountering patients during his early years as a medical student ${ }^{9}$. The curriculum and the way in which it is run enhances the development of a student's professional identity, through problem-based learning, early clinical exposure, and integrated interprofessional education?. Brandt learned significantly from the opportunity to work with other healthcare professionals. This collaboration allowed for the understanding of different perspectives as each healthcare professional approached each case from a different angle.

Through the use of experiential learning in clinics with multidisciplinary teams, a medical student felt better prepared to be a health professional ${ }^{9}$. Therefore, experiential learning in the early years of study allows a smoother transition from theoretical studies to a working professional. This transition can aid in further professional identity development. The main factors in the curriculum that were helpful in developing the professional identity formation of medical students were, the multidisciplinary healthcare settings, and the patient contact throughout the years of study, as more skills were learned with regards to communication and being client-centred or more empathetic?.

Three categories of professional identity emerged during the process of professional identity development in graduating Physiotherapy students ${ }^{10}$, namely that of the 'empowerer', the 'educator' and the 'treater'. The 'empowerer' is interprofessional, the 'educator' is a rehabilitation professional, and the 'treater' is uni-professional. Studies exist that discuss how the socialisation processes amongst students influence the development of professional identity and how the students view themselves at the end of their studies as health care professionals. Educators are paying attention to educational outcomes of professional training curricula which are intended to ensure that graduating students are fit to practise. However, this does not necessarily improve nor facilitate the development of professional identity ${ }^{10}$.

The strength of professional identification however, varies by profession. The significant contributors of baseline professional identity were: gender; profession; previous work experience in environments; understanding of team work; knowledge of profession; and cognitive flexibility ". In their study, Lindquist et al. " suggest that students who demonstrate a particular affinity or identification with the profession are likely to gain admission to the course rather than those with lower levels of identification. The strongest professional identities were found in physiotherapy students, while social work students had the weakest professional identities when compared to other professional groups ${ }^{\prime \prime}$.

Studies have shown that interdisciplinary practice is one example of how curricula could encourage the development of professional identity across varying professions.

The research question How is the professional identity of final year H\&R students being shaped over the course of four years of study? was pertinent as it contributed to unearthing the professional identity development of H\&R students. The study therefore aimed to describe the factors that contributed to developing professional identity for H\&R students within a higher education environment.

\section{METHODS}

Design: A descriptive qualitative design ${ }^{12}$ was used as it appropriately addressed the research question in describing how professional identity is developed and shaped by the contextual factors and higher education environments students find themselves in. The study was conducted at a Health Sciences Faculty at the University of Cape Town.

Sampling: Purposive sampling was used to identify seven participants who met the selection criteria. The participants included students studying occupational therapy, communication science disorders and physiotherapy. To allow full anonymity and confidentiality, each participant was asked to choose a fictional name, which allowed for full anonymity whilst providing a personal voice. Selection criteria: Participants had to be final year occupational 
Table I: Participant demographics

\begin{tabular}{|l|l|l|}
\hline Pseudonyms & $\begin{array}{l}\text { Race (Black, White, } \\
\text { Coloured, Asian) }\end{array}$ & $\begin{array}{l}\text { Gender (Male, } \\
\text { Female) }\end{array}$ \\
\hline Alice & White & Female \\
\hline Annie & Coloured & Female \\
\hline Jaydine & Coloured & Female \\
\hline Patrick & Black & Male \\
\hline Tsholofelo & Black & Female \\
\hline Bob Jenkins & White & Male \\
\hline Cami & Indian & Female \\
\hline
\end{tabular}

therapy, physiotherapy and communication sciences disorders students in 2018. Students who had studied at least one year in another degree other than their current degree were excluded from the study.

Participant recruitment: An invitation to participate in the research was sent to class representatives and was sent to final year students across the disciplines via an email that included the information sheet and the informed consent form. The information sheet to recruit potential participants were also presented during a lecture slot to further attract participants.

\section{*Ethical clearance:}

Ethics approval (HREC 034/20I8) for this study was granted from Human Research Ethics Committee, Faculty of Health Sciences at University of Cape Town (UCT)and the Director of Student Affairs at UCT prior to data collection.

The participants included two of each race and one Indian as specified in Table I (p5I), two males and five females and two of each discipline, apart from Communication Sciences Disorder where there was only one participant. The participants' disciplines were omitted from Table I to further ensure anonymity, as the class sizes were small and could potentially enable identification of individual participants..

Data collection: Individual interviews with each participant were conducted taking an interview guide approach. The interviews were 40 minutes long and were held at a place that was convenient for the participants. The interviews were audio-recorded with the consent of all participants. A focus group session on the themes that emerged from the interviews was conducted to further develop emerging themes. The focus group session contained six participants as one participant was not available. The participants included two occupational therapy students, two from communication science disorders and two physiotherapy students. This assisted in consolidating the data that emerged from the interviews and served as a form of member checking.

Data Analysis: An inductive approach was employed to analyse the information received from both the interviews and the focus group. The audio-recording of the interviews were transcribed verbatim. The transcripts were then analysed through a thematic analysis approach. The themes were used to inform the questions for the focus group. The focus group was audio-recorded and transcribed verbatim, the data were then grouped into the final theme.

Rigour: Rigour was ensured through the following strategies.
Table II: Theme and Sub-Themes

\begin{tabular}{|l|l|}
\hline Theme & Sub-themes \\
\hline The curriculum and experiences within & Spaces for reflection \\
\cline { 2 - 2 } $\begin{array}{l}\text { practice and professional environments } \\
\text { shape professional identity the most. }\end{array}$ & $\begin{array}{l}\text { Practical experience over } \\
\text { theoretical knowledge }\end{array}$ \\
\cline { 2 - 2 } & $\begin{array}{l}\text { Lack of curricular spaces } \\
\text { that allow for intersec- } \\
\text { tions of professions }\end{array}$ \\
\hline
\end{tabular}

Dependability ${ }^{20}$ : Consistency in procedures with all participants was ensured by having a set interview question guide and ensuring that the same researcher interview all the participants.

Credibility ${ }^{20}$ : The findings were member-checked with the participants through a focus group to ensure accuracy of data that were captured.

Transferibality ${ }^{20}$ : This was ensured through documenting a clear research process using an audit trail.

\section{FINDINGS}

The following theme emerged 'The curriculum and experiences within practice and professional environments shape professional identity'.

This theme focuses on the way in which undergraduate curriculum programmes are structured and the opportunities afforded students through professional environments such as practice learning, that contribute to the development of their professional identities.

\section{Sub-themes:}

\section{Spaces for Reflection}

This sub-theme focused directly on what each programme had to offer as a space to reflect on the learning and experiences that occur during practice learning, as well as the personal experience each student encounters within each site. Tutorials are one learning strategy used over several platforms across the H\&R programmes where this type of sharing of experiences occurs. Three out of the four programmes offer these type of tutorial spaces. Only one programme in $H \& R$ has a time scheduled for reflective space within their course curriculum.

Becoming a Rehabilitation Professional and Clinical Physiotherapy are two courses that have influenced the professional identity of one of the Physiotherapy participants as these courses taught them how to act and think as a professional in a practical and theoretical sense. However, it was not a space that encouraged reflection on clinical experiences and personal identity and positioning.

"...overall I feel like both clinicals and this course allow me to at least encompass both of those that add towards my professionalism." - Tsholofelo

Patrick provided an example of an experience he was able to share during a reflective space that positively helped him to make sense of the experience. This incident occurred during practice learning with a clinician.

"I had to interact with someone who every time they saw me they saw a representation of what was wrong with their life. So, problems they were facing like they got burgled into and it was by 
criminals who were supposedly black, there were protests at UCT and it meant that her daughter was going stay longer in the year and she was going to get paid more. But every time she saw me she thought, "These people". So, I was the reminder, she projected her problems onto me and then I was the horrible one. So yeah. I called her racist at the end, and she cried and I was like it's fine, you just have to admit that you're racist." - Patrick

The above quote from a student experience in practice, provides one example of how one can be perceived just by your appearance. He had to learn how to negotiate his personal identity with his professional identity in thinking about how to best respond to the situation he was in.

The participants in the study communicated that their professional identity reflected their personal identities, namely seeing how their cultural and gender identity can fit into their professional identity and how this affects their ability to practice. Jaydine described it as:

"We have two Muslim HODs in the OT department. ... it just instilled so much confidence in my personal identity as a coloured Muslim in this profession". For Patrick, connecting on cultural level was more valuable "I think for me, it's important for me to see people who I relate to on a cultural level doing what I aspire to do." - Jaydine

These two examples demonstrate that the formation of a professional identity was influenced greatly by who they are as individuals; which is considered to be factor that contributes to the process of developing a professional identity.

Gender was one of the personal identities that was highlighted by the participants in playing a role in the formation of a professional identity. There is a lack of male representation in some departments in the FHS, particularly occupational therapy and communication sciences disorders. The effects of this include being unable to position oneself within the profession, may deter from professional identity as well as having concerns for his own cultural responsibilities financially. A lack of representation was noted by a male participant in the study who commented on how this has led to a shortage of clinical male occupational therapists. There is a need for more male representatives in H\&R in the form of role models, as these professions are deemed as being female dominated, resulting in males being less visible. Many male H\&R professionals choose to work in the corporate sector and not in the health sector as it may be seen as more financially viable. The inability for participants to identify themselves within the profession in terms of their personal identity affects their self-efficacy.

"So, I still haven't met someone who is married and has had to make it work being an OT and you know, pay black tax. Not pay in like transaction way, but go through that experience of having to help out at home and still have a life of their own and start a family and go through the all cultural processes of a wedding, paying lobola, and make it work and see how it looks like for a black person who is an OT and who has had to go through all of that. So, for me, I still haven't seen anyone like that, and that's why I say that I haven't met a role model, I've met people that I aspire to, that I can draw inspiration from and say, I can learn from what this person has done or what they have achieved or what they have learnt through doing certain things." - Patrick
The sub-theme explored the different spaces for reflection that exist in H\&R programmes. The occupational therapy division has a designated space for this type reflection which supported some participants' experiences of difference and how these experiences influenced their developing professional identity as a growing student. Other participants expressed that their divisions should also have a space available similar to that of the occupational therapy division:

"I think because you guys are studying occupational therapy you have something specifically dedicated to identity, whereas we don't." Cami

\section{Practical Experience over Theoretical Knowledge}

This sub-theme speaks to the experience that students acquire at practice learning as it relates to the theory that has been taught and the impact this experience has on their roles as emergent health professionals. Positive feedback from clients also helped to reassure the participants that their roles are important and that they are making a difference to the clients' lives. H\&R students have had reported good interactions with their clients.

"Watching people be grateful when we give them hearing aids". - Annie

Participants believed that teaching theory on its own is not enough to equip them with the necessary skills they require to thrive in a clinical setting. They have raised concerns about the role of theory in other professions towards developing their professional identity. Participants also indicated that the tutorials they have had during practice learning with their supervisors have been helpful in guiding their interventions:

"You can give a student an idea [of their role] but they're not going to know until they're there". - Alice

"We do have a lot of tutorials in block where we can just come and talk about our experiences at clinics". - Cami

This sub-theme explored how positive client interactions shape professional identity, as well as how the combination of theory and practice that is experienced during practice learning can help students to discover their role, and these interactions have either a significant positive or negative impact on the participants' professional identity.

\section{Lack of Curricular Spaces that Allow for Intersections of Professions}

Interactions amongst one's peers also may shape the professional identity of a student through one's time at university. The number of social interactions amongst one's peers varies between courses due to schedules, physical settings and practice learning placements. The participants felt that their professional identity was impacted due to the lack of interactions between various health professionals.

The different professions have often been grouped together for certain courses as well as in different venues, which render socialisation between the other divisions to a minimum throughout the four years. As the number of students in each programme varies greatly, venues across the large campus are required, limiting opportunities for student interactions. This provides them with fewer 
opportunities for socialisation outside of their profession and they often experience feelings of isolation.:

"The physios are worse than the medics, like we don't really interact with the medics, so they don't bother me at all." - Cami

“We don't really have meridian, so we don't really interact and we all get sent here at Old Main and then you never see like the doctor students again". - Alice

The only apparent space for the different disciplines to interact is on the bus to the different practice learning sites. This is an opportunity for social interaction amongst different professionals but this is also dependent on practice learning placement, as students are not guaranteed transport to certain placements and if transport is provided, students would only be able to interact with others going to placements in the same geographical area.

"And then when your clinics start and you like take the buses together and stuff then you can interact more with the physios and the OTs" - Alice

During the focus group, whilst participants were discussing the divisions in the faculty, an issue about hierarchy in H\&R surfaced, the participants came to the consensus that physiotherapists were seen as and acted as if they were at the top of the H\&R food chain:

“Um ... like the physios, definitely, I won't say all of them, um most of them think they better than the rest of us. (Laughter). The OTs, Audios and Speeches are of the same sort of level".- Cami

"I've heard of that hierarchy thing amongst health and rehab. Um some OTs have come forward to me at one point in time and told me that um or asked like why we feel as if we're like the next thing or the next best thing to medicine". - Tsholofelo

Apart from Becoming a Professional (BP) and Becoming a Health Professional (BHP) course in first year, there is no other space available for different professions to interact with each other. In summary, this sub-theme speaks to how the lack of interaction between the different divisions within the FHS contributes to the dynamics on campus, ultimately perpetuating a hierarchy due to the lack of knowledge and disregard of the different professional roles within the health care setting.

\section{Discussion}

The model of 'transactionalism' offers a lens to view an individual as not being a separate entity outside of their context ${ }^{15}$. This model aligns with the findings that professional identity reflects a person's personal identity. Professional identities of occupational therapists have been less strongly defined due to a lack of understanding of the nature and purpose of occupational therapy'. The findings of this study have found the opposite of what Mackey ${ }^{15}$ suggested exists in the department of H\&R at UCT. Occupational therapy students appeared to have a stronger understanding of their professional identities in clinical practice compared to their colleagues in the other health professions. The formation of professional identity begins even before students enter tertiary education and then evolves during studying, clinical experiences and subsequent careers ${ }^{5}$, which concurred with what participants Alice and Annie said about their personal identities being reflected by their professional identities.
This implies that each student's formation of professional identity will vary according to who they are even though they are taught the same content throughout their university career.

It was noteworthy that no female participants brought up the lack of male representation in their respective divisions. There is an assumption that this lack of representation was not noted by the female participants due to the lack of direct impact on their daily experiences, because the H\&R department is female dominated. Productivity is encompassed by the social recognition that individuals attach to their work ${ }^{6}$, the devaluing of $H \& R$ professionals' roles within the multidisciplinary team is likely to have an impact on their productivity as it relates to occupational identity. This may occur when H\&R professionals are not recognised, respected or their roles not acknowledged and undermined; therefore, affecting the meaning and value a person assigns to their productivity. These negative social transactions shape professionals' occupational identity and contribute to poor performance levels in the healthcare setting.

According to Phelan \& Kinsella ${ }^{6}$ social dimension speaks to the way in which society and social structures are able to influence the occupations that individuals engage in, and therefore act to shape their occupational identity. It was found that the use of reflective journals brought awareness of values that guide physicians' interactions with patients and enhance professional identity formation ${ }^{4}$. Many authors found that professional identity formation is largely reliant on the combination of theoretical knowledge and practical experience ${ }^{16,5,9}$. To a large extent the participants of this study agreed with this as they found that learning theory alone was not as effective if it could not be implemented practically, in that theoretical knowledge is not solely sufficient for the skills in their scope of practice.

\section{Structures that perpetuate the divide}

The structural positioning of the FHS campus contributed to the divide amongst the departments of $\mathrm{MBChB}$ and $\mathrm{H} \& \mathrm{R}$ through the delegation of faculty resources and physical learning spaces. Being on the Health Sciences campus comes with the convenience of easier access to administration offices and faculty resources for medical students further isolating the H\&R students and potentially limiting access to learning and further support. This could also contribute to how H\&R students position themselves in relation to medical students. Nembhard and Edmondson ${ }^{17}$ agreed that on higher status individuals, in this case $\mathrm{MBChB}$ students, receive tangible benefits that those who are lower ranked. The second structure that perpetuates the divide amongst healthcare professionals is curricula. Johnson ${ }^{5}$ emphasised the importance of education and its effects on professional identity as this is when professionals gain the professional knowledge and skills that distinguish them from other occupations. The participants felt that what the curriculum offered in terms of interprofessional learning was not sufficient as it was only done in the first year of study, where they had not yet fully understood their own role in the healthcare system. The attempts of Becoming a Health Professional and Becoming a Professional courses on interprofessional learning ${ }^{18}$, were not seen to be as effective as hoped because participants felt that they did not find these courses useful.

The broad issues discussed, offered an explanation to the factors that influence how professional identity is shaped for health and rehabilitation students. These factors either hindered or supported the students development in varying ways, that then continue to perpetuate the hierarchy that currently exists in the higher education environments. 


\section{Implications for practice}

This study offers insights into how curricula can positively shape and contribute to the developing self as an emergent health professional. By taking into careful consideration the content we include in occupational therapy undergraduate curricula and the practice sites we use, this can ensure that every student finds resonance with the experience.

\section{Limitations}

The only limitation of this study was that it focused on student perspectives from one university and therefore findings are contextually relevant to that one university only.

\section{Conclusion}

This article highlighted and brought to the fore how critical events in higher education may have influenced the participants developing professional identity as Health and Rehabilitation students. The curriculum plays an integral role in defining how the narrative for each participant plays out and how professional and practice environments greatly shape the students' developing self.

\section{Recommendations}

It is recommended that health sciences programmes consider opportunities in their curricula to include content on reflection of professional identities as fundamental to contributing to their developing and emerging identities as health professionals.

\section{REFERENCES}

I. Mackey H. 'Do not ask me to remain the same': Foucault and the professional identities of occupational therapists. Australian Occupational Therapy Journal.2007; (54): 5-102. https://doi.org/10.1 I II/j.1440-1630.2006.00609.x

2. Matthews J, Bialocerkowski A. \& Molineux M. Professional identity measures for student health professionals - a systematic review of psychometric properties. BMC Medical Education. 2019; 19: 308. https://doi.org/10.1 186/s 12909-019-1660-5

3. Cloete N, Maassen P, Bunting I, Pillay P, \& Bailey T. Universities and economic development in Africa. 20II Retrieved from https://chet.org.za/download/file/fid/70

4. Bassier, I, Velelo, L, Coenraad, S, Chikte, A, Wenana, C, \& Murithi, G. Protesting policy: Interrogating free decolonised higher education funding. 2015; Retrieved from

https://www.news.uct.ac.za/images/userfiles/files/downloads/ fepg/ FundingFreeDecolonisedEducation_Long.pdf

5. Branch W, \& Frankel R. Not all stories of professional identity formation are equal: An analysis of formation narratives of highly humanistic physicians. Patient Education And Counseling.2016; 99(8), I394-1399. http://dx.doi.org/10.1016/j.pec.2016.03.018

6. Johnson M, Cowin L.S, Wilson I and Young H. Professional identity and nursing: contemporary theoretical developments and future research challenges. International Nursing Review. 2012; (59): 562-569. https://doi.org/10.1 I I I/j. I466-7657.2012.01013.x

7. Phelan S, \& Kinsella E. Occupational Identity: Engaging Socio-Cultural Perspectives. Journal of Occupational Science 2009; 16(2),85-91. https://doi.org//0.1080/14427591.2009.9686647

8. Miller G, \& Nowacek D. Social construction of reality. The Blackwell Encyclopedia of Sociology. 2018; John Wiley \& Sons Ltd. https://doi.org/10.1002/978|405I655I8.wbeos I 232

9. Sonday A, Ramugondo E, \& Kathard H. Professional role transgression as a form of occupational consciousness. Journal of Occupational Science, 2019; 26(3), 366-378. https://doi.org/10.1080/14427591.2019.1630852

10. Brandt L. Personal professional identity formation through interprofessional learning and early patient encounter during preclinical years. Korean Journal Of Medical Education. 2017; 29(3): 203-205. http://dx.doi.org/10.3946/kjme.2017.67

I I. Lindquist I, Engardt M, Garnham L, Poland F, \& Richardson B. Physiotherapy students' professional identity on the edge of working life. Medical Teacher. 2006; 28(3): 270-276. http://dx.doi.org/10.1080/01421590600605272

12. Turner, J. C., \& Onorato, R. S. Social identity, personality, and the self-concept: A self-categorizing perspective. In Applied social research. The psychology of the social self .T. R. Tyler, R. M. Kramer, \& O. P. John, Editors. Lawrence Erlbaum Associates Publishers. 1999: I I-46.

13. Sandelowski M. What happened to qualitative description? Research in Nursing \& Health. 2000; 23 (4): 334-340.

https://doi.org/10.1002/1098-240X(200008)23:4\%3C334::AIDNUR9\%3E3.0.CO;2-G

14. Christiansen C.H. Defining lives: Occupation as identity: An essay on competence, coherence and the creation of meaning. American Journal of Occupational Therapy. 1999; 53: 547-558. https://doi.org/10.5014/ajot.53.6.547

15. Christiansen C. Identity, personal projects and happiness: Self construction in everyday action. Journal of Occupational Science. 2000; 7: 98-107. https://doi.org/10.1080/14427591.2000.9686472

16. Dickie V, Cutchin M, \& Humphry R.(2006). Occupation as Transactional Experience: A Critique of Individualism in Occupational Science. Journal Of Occupational Science. 2006; I3(I): 83-93. http://dx.doi.org/10.1080/1442759I.2006.9686573

17. Ikiugu M, \& Rosso H. Facilitating professional identity in occupational therapy students. Occupational Therapy International. 2003; 10(3): 206-225. http://dx.doi.org/10.1002/oti. 186

18. Nembhard I.M. \& Edmondson A.C. Making it safe: The effects of leader inclusiveness and professional status on psychological safety and improvement efforts in health care teams. Journal of Organizational Behavior: The International Journal of Industrial, Occupational and Organizational Psychology and Behavior. 2006; 27(7): 94I-966. https://doi.org/10.1002/job.413

19. Mayers P, Alperstein, M, Duncan, M, Olckers, L. \& Gibbs, T. Not just another multi-professional course! Part 2: Nuts and bolts of designing a transformed curriculum for multi-professional learning. Medical Teacher. 2006; 28(2): 152-157. http://dx.doi.org//0.1080/01421590600603137

20. Creswell, J.Qualitative Inquiry and Research Design: Choosing Among Five Approaches. 3rd edition. SAGE publishing: Washington DC. 2013 :47-49.

\section{Corresponding Author:}

Amshuda Sonday

Email: a.sonday@uct.ac.za 